\title{
Ética de la medicina gestionada
}

\author{
Ethics of managed medicine
}

\author{
Carlos Celedón L1.
}

\begin{abstract}
RESUMEN
La escuela filosófica "principialista" se basa en cuatro principios fundamentales cuales son: justicia; beneficencia; no maleficencia y autonomía. Este último adquiere un gran desarrollo a partir de la década 1970-1980. Así como la autonomía llevada a un extremo puede ser un obstáculo para la relación médico paciente, lo es también la "economía". Al desarrollarse el concepto de atención sanitaria, como un derecho ciudadano de justicia social; surge el problema de financiamiento de esta atención. Los economistas acusan a los médicos de no valorar lo que es la gestión en salud y la priorización de los recursos ya que éstos son limitados. La validez que tiene la gestión tanto administrativa como financiera en salud puede distorsionarse cuando a ésta se la considera un fin y no un medio. El fin de la medicina es la atención del paciente y la economía es un medio para lograr ese fin. Nunca el lucro puede ser lo que mueva a la economía sanitaria: por eso que es tan discutible el uso de términos como cliente en vez de paciente o empresa en vez de clínica u hospital.
\end{abstract}

Palabras clave: Ética, relación médico-paciente, economía.

\begin{abstract}
The "principlism" philosophical school is based on four fundamental principles: justice, beneficence, nonmaleficence and autonomy. The latter acquired great development starting on the 70s-80s. Autonomy taken to an extreme could be an obstacle for the physician-patient relationship; so it is "economy". As the concept of sanitary care as a social justice citizen right developed, the problem of financing the care provided arose. Economists blame physicians for not appreciating health management and resource prioritizing, given the limited nature of the latter. The validity of administrative and financial health management could be distorted when it is considered a goal and not a means. Patient care is the goal of medicine and economy is a means to attain this goal. Profit could never be the motor of health economy: That is the reason why the use of terms such as client instead of patient, and company instead of clinic or hospital are debatable.
\end{abstract}

Key words: Ethics, physician-patient relationship, economy.

\footnotetext{
1 Médico Otorrinolaringólogo, Hospital Clínico de la Universidad de Chile.
} 
La ética médica en la cultura occidental deriva del principio hipocrático de "favorecer y no perjudicar" que a la larga se ha concretado en los principios de "beneficencia" y el de "no maleficencia". De acuerdo al principio de "beneficencia" es el "médico el que sabe" y del que se espera que haga un "buen diagnóstico y tratamiento"; frente a una persona (paciente) enferma que sufre y por ende pide ayuda al experto médico que es quien sabe ${ }^{1-2}$. Esta relación médico-paciente asimétrica y paternalista se ha hecho cada vez más engorrosa debido a la mayor complejidad de la medicina y de los proveedores de salud. En la década de 1970-1980 emerge con gran fuerza el concepto de autonomía en la relación médico-paciente. El desarrollo de este concepto se debe a:

a) Abuso de los investigadores con pacientes en la investigación biomédica lo que lleva a protegerlos, desarrollándose el "consentimiento informado"; que no es otra cosa que la expresión por escrito de su autonomía. Algunos casos emblemáticos de esos abusos son la investigación en seres humanos hechas por el nacional socialismo en los campos de concentración en la Segunda Guerra Mundial; el caso Tuskegee (Alabama) en el cual se les negó el tratamiento contra la sífilis a personas de raza negra para observar el curso natural de la enfermedad 0 bien el caso Willowbrook en el cual se inocularon virus de la hepatitis $B$ a niños enfermos mentales ${ }^{3}$.

b) La medicina moderna es cada vez más intervencionista y con gran capacidad de curar y paliar enfermedades que antes no tenían remedio. Ejemplo de ello son los trasplantes de órganos o la ventilación mecánica. Ambos procedimientos pueden plantear dilemas éticos serios.

c) La medicina actual tiene gran impacto en modificar la vida de las personas. En la actualidad más personas son salvadas en la UTI y muchas veces con dudosa calidad de vida. ¿Hasta cuándo es lícito prolongar la vida a una persona conectada a ventilación mecánica? ¿No estaremos en presencia de un ensañamiento terapéutico?

d) Mayor conocimiento y educación médica de la población lo que lleva muchas veces a cuestionar el tratamiento propuesto por el médico. En la actualidad no es raro que los pacientes que consultan una opinión médica ya se hayan informado sobre su patología por Internet.

e) El desarrollo tecnológico de la medicina tanto para el diagnóstico como para el tratamiento, ha llevado a encarecer los costos de ella. No es infrecuente que los pacientes no estén dispuestos a someterse a costosos diagnósticos 0 tratamientos no estando seguros si los resultados serán del todo beneficiosos ${ }^{3-7}$.

Todo lo anterior ha llevado a los pacientes a rebelarse del antiguo paternalismo hipocrático y en la actualidad exigen información y participación en la decisión de sus tratamientos médicos.

La filosofía nos aporta muchas teorías éticas para resolver problemas concretos en el ámbito de la salud. El "principialismo" es uno de ellos. Nos referiremos a él por ser quizás el más práctico para la toma de decisiones en clínica e investigación médica.

En el año 1979 se publicó el libro "Principios de la Ética Biomédica" de los autores Tom Beauchamp y James F. Childress. En este libro se establecen y fundamentan los cuatro principios básicos de lo que hoy conocemos como "principialismo" y que son: autonomía; justicia; beneficencia y no-maleficencia-9.

Así como en los años 1970-1980 se incorpora el concepto de "beneficencia no paternalista" al surgir el "consentimiento informado" (autonomía); el principio de beneficencia propio de la cultura occidental desde la época de Hipócrates, se ve nuevamente acorralada, ahora no por el principio de autonomía sino que también por la economía. La asistencia sanitaria deja de ser una cosa entre privados y pasa a ser un asunto de justicia social, primando el derecho moral a la asistencia sanitaria, basado en la idea de justicia social. La asistencia sanitaria pasa a ser una exigencia ética de justicia. En otras palabras queda aún más claro que la economía es un medio para la justicia social y no un fin en sí mismo. Desgraciadamente en la actualidad muchas veces se confunde el rol de la economía en la atención de salud ya que se pone los principios económicos al servicio del lucro en la atención de salud y no al servicio de la "asistencia sanitaria." Conceptos como cliente en vez de paciente 0 empresa en vez de hospital o clínica, ha 
llevado a un choque conceptual entre médicos y economistas acerca de lo que se entiende por "atención sanitaria".

En los años 80 se revisa la idea de bienestar sanitario por la necesidad de controlar los gastos en salud. La exigencia de justicia chocaba con los escasos recursos de que se disponía en salud, lo que obligaba a enfrentarse a problemas de "financiamiento" y "gestión". Los economistas acusan a los médicos y a los políticos de irresponsabilidad en la gestión de los recursos de sanitarios y de esta manera nace la "economía de la salud"; la cual se propuso introducir la "racionalidad económica" en el campo sanitario, lo cual choca con el principio médico tradicional, cual es el de beneficencia. Surge de esta manera la "medicina gestionada", la cual trata de conjugar "eficiencia" con "equidad". Con la incorporación de la economía en la gestión de salud y por ende la "racionalidad económica en salud", se incorpora un cambio en la cultura médica tanto en la relación médico-paciente como en la relación entre los mismos médicos; todo lo cual pone en riesgo la eficiencia sanitaria. No todo es reducir gastos sino darle un sentido a toda la política sanitaria: saber para qué, cómo y por qué.

Para que exista real justicia social en la asistencia sanitaria tiene que haber eficiencia en el manejo de los recursos en salud, pero esta eficiencia debe ser requerida por la justicia y no una presunta eficiencia ajena a toda perspectiva de justicia social. Si la medicina gestionada pretende ser un modo de organizar la sanidad, será preciso averiguar si se mueve sólo por el afán de reducir costos, o si realmente es éste un medio para lograr una mayor justicia social y equidad en el ámbito sanitario. Es entendible que para un economista su fin sea reducir costos a objeto de hacer más rentable los recursos sanitarios. El fin médico es otro: es el paciente. Optar por el paciente sin desmerecer el financiamiento y la gestión en salud, es poner en el centro de todo el quehacer sanitario a la "persona enferma" y no la rentabilidad de los recursos en salud. En otras palabras es tomar al paciente como un fin y no como un medio.

Para evaluar éticamente el modelo de medicina gestionada, es necesario tener claro los fines de la medicina y la jerarquización funcional de la gestión como "medio" para lograrla. Existen diferentes formas de gestión en medicina. Se debe optar por aquella que sea capaz de conjugar racionalidad económica y justicia. Conviene recordar que la "empresa sanitaria" es una organización e institución que se legitima racionalmente a partir de fines objetivos (justicia) o intersubjetivos (curar y cuidar) y no por ser un mero negocio ${ }^{7}$.

El cambio cultural de la sociedad actual en la que se derrumban las certezas y los conceptos éticos parecen tambalear, es necesario reflexionar sobre el sentido final de lo qué es ser médico, única manera de no perderse en esta vorágine de lo relativo y poder mantener en alto los valores éticos hipocráticos.

Cualesquiera que puedan ser las motivaciones tanto médicas como las del paciente, lo que busca en el fondo el paciente es ser tratado con competencia profesional y como persona. El tratar a un paciente como persona es tratarlo como un ser racional y libre². Racional ya que se le debe tratar como un igual y por consiguiente explicarle su enfermedad, sus alternativas terapéuticas y su pronóstico; y libre ya que es el paciente quien debe decidir con qué médico se trata e incluso si acepta tal o cual tratamiento o no aceptar ninguno. Es precisamente al servicio de este paciente que debe estar disponible la gestión tanto financiera como administrativa en salud. Siempre el fin de la atención sanitaria debe ser el paciente y no las utilidades que produce el negocio de la salud, por legítima que sean ${ }^{10}$.

\section{BIBLIOGRAFÍA}

1. Celedón C. Editorial: Desafíos en la relación médico-paciente. Rev. Otorrinolaringol. Cir. Cabeza Cuello 2003; 63: 93-4.

2. Celedón $C$. Editorial: Concepto de persona en la relación médico-paciente. Rev. Otorrinolaringol. Cir. Cabeza Cuello 2002; 62: 227-37.

3. LoLAs F. Bioética: El diálogo moral en las ciencias de la vida. Editorial Mediterráneo Ltda. 2001; Pág. 19-37.

4. Rosselot E. La relación médico-paciente: En un nuevo paradigma bioético. Boletín Científico Asociación Chilena de Seguridad 3; 5-6, dic. 2001; 95-9.

5. Serani A. La relación médico-paciente y el problema de la mercantilización de la medicina. 
Boletín Científico Asociación Chilena de Seguridad 3; 5-6, dic. 2001: 47-9.

6. Ventura-Juncá P. La relación médico-paciente: ¿Autonomía o beneficencia? Boletín Científico Asociación Chilena de Seguridad 3; 5-6, dic. 2001; 62-7.

7. ConIL J. Horizontes de Economía Ética: Aristóteles, Adam Smith, Amastya, Editorial TECNOS, 1 a edición año 2004 Madrid, capítulo IV: Economía Ética de la Empresa Sanitaria, pág. 247-82.
8. Beauchamp $T$ and Childress F. Principles of Biomedical Ethics. Oxford University Press, New York, 1979.

9. Requena P. Modelos de Bioética Clínica, presentación clínica del Principialismo y la Casuística. Editorial de la Santa Cruz, Roma año 2005.

10 Moreno F. Economía, política y moral Pág. 241246; en Lavados M., Monge J., Quintana C., Serani A. Problemas Contemporáneos de Bioética. Ediciones Universidad Católica de Chile año 1990. 